\title{
Demographic and functional responses of wild dogs to poison baiting
}

\author{
By Lee R. Allen
}

Lee R. Allen is a Senior Zoologist with Biosecurity Queensland (Robert Wicks Pest Animal Research Centre), Department of Agriculture, Fisheries and Forestry, (PO Box 102, Toowoomba, QLD 4350, Australia; Tel: +61 70467 805389; Email: lee.allen@daff.qld.gov.au.

\begin{abstract}
Summary Lethal control of wild dogs - that is Dingo (Canis lupus dingo) and Dingo/ Dog (Canis lupus familiaris) hybrids - to reduce livestock predation in Australian rangelands is claimed to cause continental-scale impacts on biodiversity. Although top predator populations may recover numerically after baiting, they are predicted to be functionally different and incapable of fulfilling critical ecological roles. This study reports the impact of baiting programmes on wild dog abundance, age structures and the prey of wild dogs during large-scale manipulative experiments. Wild dog relative abundance almost always decreased after baiting, but reductions were variable and short-lived unless the prior baiting programme was particularly effective or there were follow-up baiting programmes within a few months. However, age structures of wild dogs in baited and nil-treatment areas were demonstrably different, and prey populations did diverge relative to nil-treatment areas. Re-analysed observations of wild dogs preying on kangaroos from a separate study show that successful chases that result in attacks of kangaroos by wild dogs occurred when mean wild dog ages were higher and mean group size was larger. It is likely that the impact of lethal control on wild dog numbers, group sizes and age structures compromise their ability to handle large difficult-to-catch prey. Under certain circumstances, these changes sometimes lead to increased calf loss (Bos indicus/B. taurus genotypes) and kangaroo numbers. Rangeland beef producers could consider controlling wild dogs in high-risk periods when predation is more likely and avoid baiting at other times.
\end{abstract}

Key words: biodiversity, kangaroo, livestock, predation, predator control, trophic cascade.

\section{Introduction}

M any large predators (e.g. Lion Panthera leo, Tiger P. tigris, Leopard $P$. pardus, Bear Ursus arctos and various canids such as Wolf Canis lupus and Jackal C. aureus, C. adustus and C. mesomelas) are managed on almost every continent because they attack livestock and threaten the viability of producers and sometimes the safety of humans (Saberwal et al. 1994; Kusak et al. 2005; Wang \& Macdonald 2006; Nyahongo \& Røskaft 2011; Schuette et al. 2013). As well as being iconic 'native' species on their respective continents, large predators can also be important keystone species that regulate prey populations on lower trophic levels (Estes et al. 2011), making the preservation of large predators critical to maintaining biodiversity and healthy ecosystem function (Johnson et al. 2007; Sergio et al. 2008; Prugh et al. 2009; Levi \& Wilmers 2012). Conflict between biodiversity conservation and agricultural production is almost inevitable and often polarised.
The Dingo and other Dog/Dingo hybrids (collectively referred to here as wild dogs) are the largest mammalian predators on mainland Australia. They were declared pests in most places by the late 1800s because of the substantial livestock losses they inflicted, primarily on sheep (Ovis aries) (Allen \& West 2013). Today, many tonnes of fluoroacetate (1080) poisoned meat bait are laid on public and private agricultural land to reduce the impact or spread of wild dogs (APVMA 2008). Where undertaken, conventional wild dog management on beef cattle properties in northern Australia is to bait in late autumn after the first round muster, at a time when wild dogs are mating and are very active (Fleming et al. 2001). A second baiting, if conducted at all, generally occurs in late spring after the second round muster prior to summer calving. Government agencies and grazier organisations encourage and facilitate the coordination of baiting programmes at these times so that large tracts of land are treated simultaneously (McKenzie et al. 2014).
Wild dogs are a well-known and serious threat to Australia's sheep industry (Allen \& Fleming 2004; Allen \& West 2013), but the attitudes of beef cattle producers to wild dogs have long been ambivalent (Allen \& Sparkes 2001). Evidence of calf predation is mostly anecdotal or indirect, but estimated livestock losses can be substantial [\$23 million in direct cattle losses in Queensland alone (Hewitt 2009)] with costs of control making up a significant proportion of the economic losses [an additional \$11 million (Hewitt 2009)]. Diet studies generally show a low incidence of cattle remains in wild dog's diets (typically $<5 \%$ ) unless cattle carcasses are being scavenged [up to $23 \%$ (Corbett 2001)] or there are few alternative prey to eat, that is central Australia 6-42\% [Allen \& Leung 2014)]. Veterinary investigations into the causes of calf loss rarely find evidence that predation was the cause of death (mortality factors reviewed in Burns et al. (2010). Manipulative experiments (Eldridge et al. 2002; Fleming et al. 2012; Allen 2014) comparing calf loss between pregnancy diagnosis and 
weaning, in treatment areas or properties with and without annual or biannual wild dog baiting, generally show that wild dogs infrequently kill detectable numbers of calves yet some properties, some years can experience severe losses. Allen (2014) reported counter-intuitive results from central-south and north Queensland showing that calf loss occurred more frequently and with greater losses where wild dogs were controlled compared to paired nil-treatment areas where they were not controlled. In that study, below-average rainfall was a significant factor associated with calf loss but only where wild dogs were controlled. This finding suggests that baited and/or recolonised wild dog populations might be functionally different to those in unbaited populations.

This paper investigates whether demographic differences exist between wild dog populations in baited and niltreatment areas. It investigates how these differences might affect prey selection in order to explain why baiting-induced calf loss was found to occur during drought subsequent to baiting, but not in nearby nil-treatment areas. Demographic differences between wild dog populations in baited and nil-treatment areas were investigated by (i) measuring the impact of baiting programmes on wild dog relative abundance, (ii) by measuring how long population reductions caused by baiting lasted before abundance returned to precontrol levels and (iii) by investigating whether changes in population age structures occurred following baiting programmes. To gain insight into how baiting may affect functional relationships, data from a separate study were reanalysed to see how group size and the age of wild dogs affect their efficiency in capturing large prey. Trends in prey populations in baited and nil-treatment areas were compared to detect whether divergences occurred indicating functional differences in the way wild dogs in baited areas interacted with their prey.

\section{General Methods}

A large-scale manipulative experiment was conducted between 1994 and 1998 com- paring calf loss and wild dog and other wildlife population trends in paired baited and nil-treatment areas on two extensive beef cattle properties located in centralsouth and north Queensland (Mt Owen and Strathmore station, respectively). The abundance of wild dogs (dingo phenotypes) and their prey was monitored from spoor, detected on tracking stations, constructed across unformed vehicle tracks [i.e. the Passive Tracking Index or PTI method reviewed in Engeman and Allen (2000)]. Relative abundance was calculated as the cumulative mean of daily mean number of tracks per tracking station per day. Precision of each PTI value was calculated using the variance method described in Engeman (2005). Further descriptions of the two study sites, the management practices, vegetation and rainfall, details of the methods of monitoring calf loss, wildlife abundance and wild dog diets are reported elsewhere in Allen et al. (2012, 2014) and Allen (2014).

At each study site, wild dog populations on a randomly selected portion of the cattle properties were routinely baited once or twice annually with $100-450 \mathrm{~kg}$ of 1080-poisoned meat bait. Baited treatment areas were $\sim 40000$ and 200 000 ha on Mt Owen and Strathmore, respectively. The remaining portion of each property (of equal or greater size than the baited area) was left unbaited and became the nil-treatment area. The two treatments were separated by a buffer zone of at least $10 \mathrm{~km}$ [i.e. approximately the diameter of one or more wild dog territories (Allen 2009)] at the closest point to provide independence between treatments at each survey.

\section{Demographic Impacts of Baiting}

\section{Wild dog relative abundance}

The impact of baiting programmes on the demography of wild dog populations was calculated as the percentage reduction in the cumulative mean number of wild dog intrusions across tracking stations per day surveyed immediately before and after baiting programmes in the baited area. As demonstrated in Allen et al. (1996) and
Allen and Engeman (2014), this method is very sensitive at detecting changes in wild dog abundance caused by baiting. The spoor of other wildlife detected on tracking stations was also identified and recorded.

On Mt Owen, 19 PTI surveys were conducted before and after seven wild dog baiting programmes where 50 tracking stations per treatment area were monitored for an average of 4.5 days per survey. Nine PTI surveys were conducted around five baiting programmes on Strathmore where 50 tracking stations per treatment area were monitored for an average of 5.8 days per survey. Surveys were conducted on average 38.9 ( \pm 8.2) days before baiting and 36.7 ( \pm 6.8$)$ days after baiting [see Fig. 1 in Allen (2014)].

\section{Duration of baiting effect}

The number of months between baiting programmes and the next survey that showed that PTI values had returned to within $10 \%$ of prebaiting PTI values was calculated to find out how long wild dog populations remain low after baiting. 'Within 10\%' allowed for variability in the calculation of the PTI. In addition, the time of year when PTI values recovered to prebaiting levels was considered in relation to peak calving times September to November (Bortolussi et al. 2005) and when predation risk to cattle might be considered greatest.

\section{Impact of baiting on wild dog age structures}

The length of the front footprint (to the nearest $0.5 \mathrm{~cm}$ excluding toe nails) of 1415 wild dog tracks was recorded from tracking stations located in both baited and nil-treatment areas (496 and 919 footprints, respectively) on Mt Owen and Strathmore during 14 PTI surveys.

Footprint data from both study sites and all surveys were summed within $0.5 \mathrm{~cm}$ footprint length categories. The proportion of the sample assigned to each footprint length category was analysed using the nonparametric, KolmogorovSmirnov two-sample test. This test is sensitive to differences in the shape of cumulative distributions of the two (footprint size) samples and is used to identify 


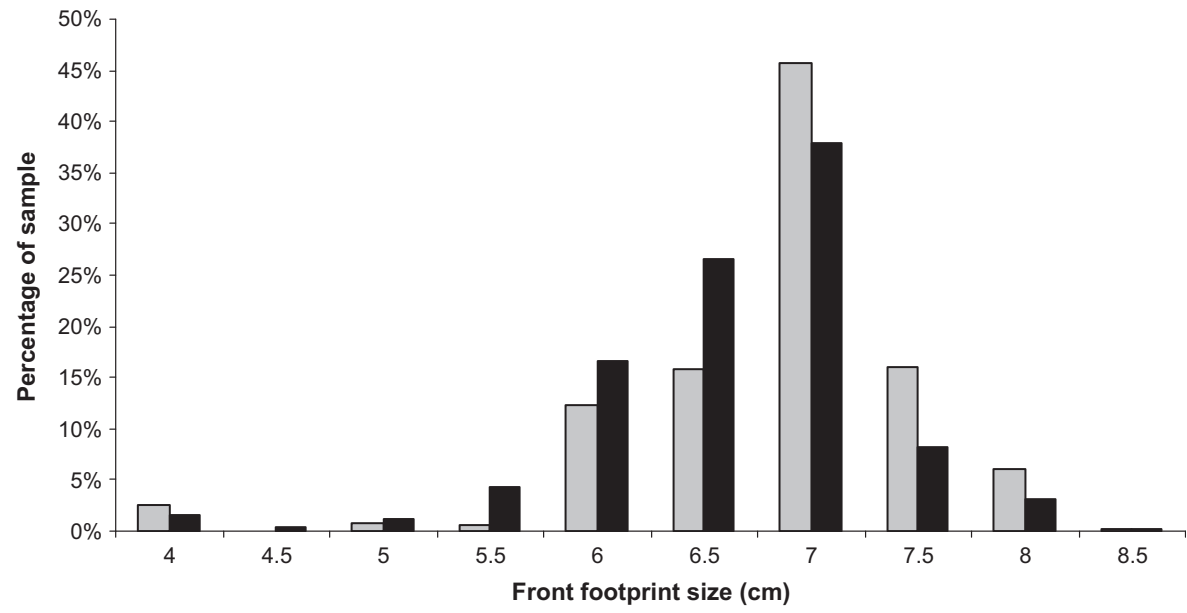

Figure 1. Distribution of mean front footprint lengths of wild dog populations measured in baited and nil-treatment (solid black columns) areas.

whether the footprint size cumulative distributions are different and where maximum deviation occurs.

To calibrate footprint length with age, the front footprint length of 33 dingoes kept in zoological gardens and sanctuaries were also measured. The age of these dingoes was calculated from birth records, and their individual footprint lengths were similarly measured from tracking stations constructed in their pens.

In a second analysis, the percentage of wild dog tracks in each footprint length category was calculated for each treatment area, pre- and postbaiting, for two consecutive baiting programmes at Mt Owen (where more frequent survey data were available). By plotting the frequency of prints in each footprint length category from survey to survey, cohorts of pups and juveniles (4-6 cm footprints) could be monitored from their first appearance on PTI tracking stations until, as yearlings $>9$ months, (Thomson 1992a), the length of their footprints became indistinguishable from the footprints of adult dogs (6.5-7.0 $\mathrm{cm}$ prints).

\section{Results}

Omitting data from stations rendered unreadable by rain, cattle or vehicles, 4124 wild dog tracks were recorded in 8739 station-nights of monitoring at $\mathrm{Mt}$ Owen. At Strathmore 4252 station-nights of tracking accumulated 800 wild dog tracks. Consistent with standard baiting practices in these areas (Allen \& Fleming 2004 ), a total of $2200 \mathrm{~kg}$ of 1080-poisoned bait was distributed in 'baited' treatment areas during the study. Variance calculations produced $95 \%$ confidence intervals that range from $2.3 \%$ to $22.1 \%$ (median of $6.5 \%$ ) of wild dog PTI values. One control programme (Mt Owen, December 1995) was not resurveyed until 5 months (171 days) postbaiting by which time wild dog PTI values had increased six- to eightfold in both treatments areas. This programme is omitted from the analysis.

\section{Impact of baiting programmes on wild dog abundance}

Eleven of 12 baiting programmes (92\%) resulted in reduced wild dog PTI values postbaiting where $95 \%$ confidence intervals did not overlap and $P$-values were $<0.05$. Wild $\operatorname{dog}$ PTI values were reduced by $>50 \%$ in nine $(75 \%)$ of these baiting programmes [see Fig. 1 in Allen (2014)], but on average a $54 \%$ reduction was achieved (range 9.1\% increase in wild dog PTI values postbaiting to $100 \%$ decrease).

Baiting programmes conducted soon after the first round cattle muster between mid-May to early August and surveyed for wild dog activity between mid-June and late August $(n=6)$ produced a mean reduction in PTI values of $51.9( \pm 18.3)$ $\%$. In contrast, wild dog PTI values in nil- treatment areas during this same period varied significantly yet on average increased by 54.4 ( \pm 49.4$) \%$. Baiting programmes conducted in late winter and spring (months during which pup rearing is occurring) which were resurveyed between mid-September and mid-November produced mean PTI reduction of $57.5( \pm 7.3) \%, n=6)$. At this same time, reductions in PTI values also occurred in nil-treatment areas $[42.0( \pm 20.2) \%$, $n=4]$.

\section{Duration of control effect}

Wild dog PTI values in baited areas generally returned to precontrol levels within 1-12 months following baiting. In most instances, recolonisation of wild dogs to precontrol levels occurred between spring and autumn concurrent with calving and weaning. One of 11 (9\%) baiting programmes reduced and maintained wild dog PTI values below precontrol levels for over 12 months. Without follow-up baiting programmes intervening, $75 \%$ or six of eight baiting programmes resulted in wild dog PTI values returning to prebaiting levels in $<8$ months. Where lethal control completely eliminated wild dog activity (e.g. Strathmore, July 1997) or was followed by a subsequent baiting programme within a few months (e.g. Mt Owen, 1994 and 1996), wild dog PTI values took longer to return to prebaiting levels.

\section{Impacts of baiting on age structures}

Analysis of front footprint length measurements between Strathmore and Mt Owen show that there was no difference in the distribution of footprint lengths between locations $\left(F=2.12_{1415,9}, P=0.14\right)$. Wild dogs in nil-treatment areas had a mean front footprint length of $6.63( \pm 0.02)$ $\mathrm{cm}$, while those in baited areas had a mean of $6.83( \pm 0.03) \mathrm{cm}$. The difference is statistically significant $(t=3.37$, df $=341, P<0.01$ ). Wild dogs in baited areas had a greater proportion of footprint length measurements in the larger footprint categories with the $\mathrm{K}-\mathrm{S}$ test on cumulative proportions showing a maximum deviation occurs at a footprint 
length of $6.5 \mathrm{~cm}(\mathrm{D}=0.18$, the asymptotic $\mathrm{K}-\mathrm{S}=3.29, P<0.00$ ) (Fig. 1).

The distribution of footprint length categories in baited and nil-treatment areas in September 1996 (Fig. 2a) shows that few juveniles (footprint lengths categories 4$6 \mathrm{~cm}$ ) occur in the baited area 3 months after baiting. The baited treatment area was baited again in late September 1996. Pups born in June-July 1996 were
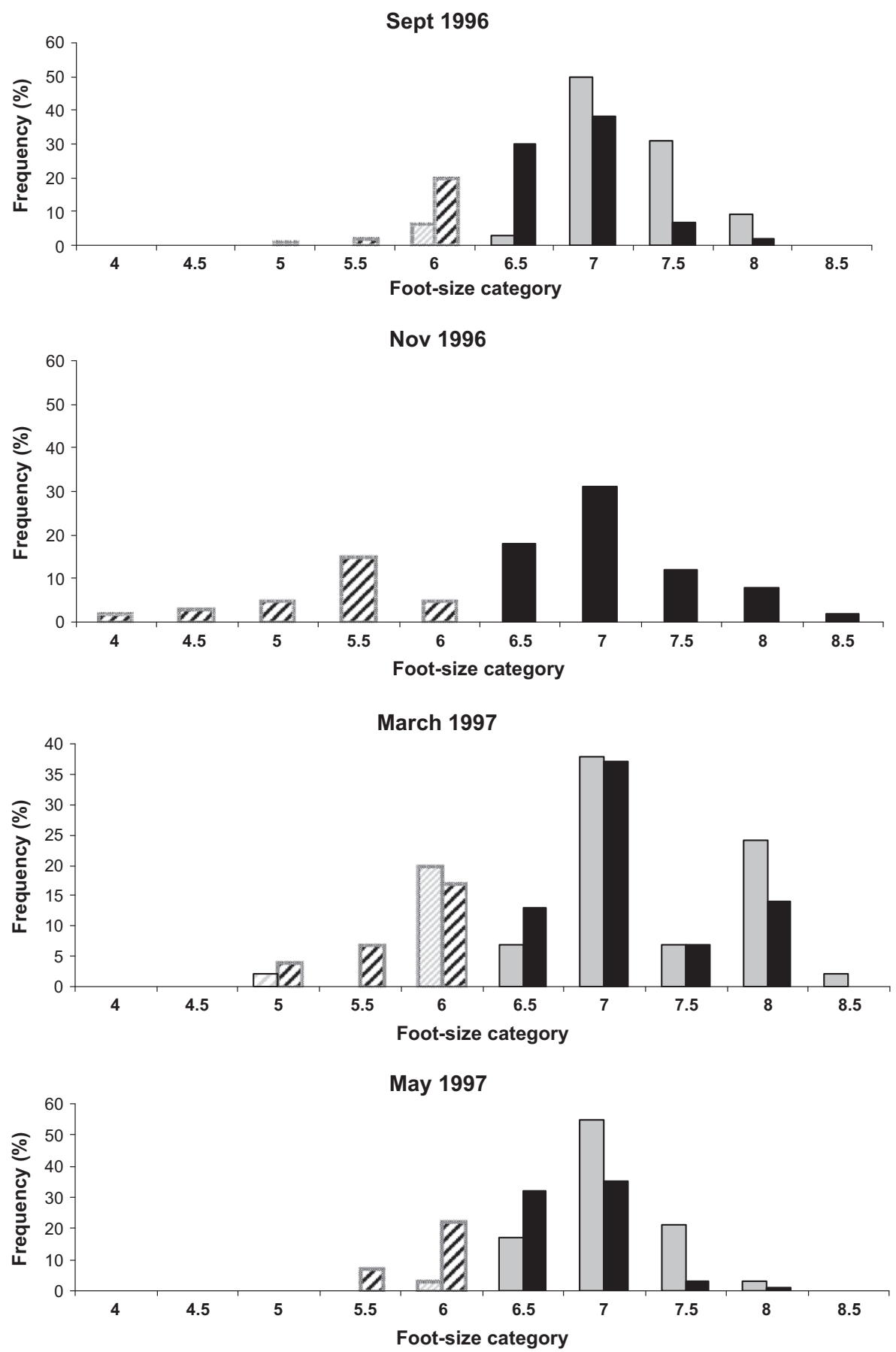

Figure 2. Proportion of the wild dog population in footprint length categories showing temporal changes in front footprint lengths of wild dogs measured in baited and nil-treated (black columns) areas in September 1996 (3 months after baiting), November 1996 (7 weeks after a subsequent baiting), March 1997 ( 6 months after baiting) and May 1997 ( 8 months after baiting). Juvenile footprints lengths $(4-6 \mathrm{~cm}$, hatched columns) eventually become indistinguishable from adults as they approach 12 months of age.

detected in the nil-treatment area in the November 1996 survey, while few wild dogs (three tracks of $5.0-5.5 \mathrm{~cm}$ ) could be found in the baited area postbaiting (Fig. 2b). By March 1997, the PTI data suggest that the wild dog population in the baited area had numerically recovered to precontrol levels (prebaiting PTI value of 0.12 in September 1996 and 0.42 in April 1997). Because November to March is the nonbreeding/dispersal season for wild dogs (Corbett 2001), such a large increase in wild dog activity in March from near absence in November, strongly indicates immigration. The distribution of footprint length categories in March 1997 (Fig. 2c) suggests that at least $20 \%$ of the immigrants were 1996-born wild dogs (i.e. front footprint lengths of 6 and $6.5 \mathrm{~cm}$ ), along with some relatively large adults $(>8 \mathrm{~cm})$. By May 1997, the distribution of prints in footprint length categories shows little difference between baited and nil-treatment areas as the 1996-born pups were now approximately 10 months old and their footprints became indistinguishable from adult wild dogs (Fig. 2d).

\section{Baiting Effects on Wild Dog Functional Relationships}

If baiting reduces population size (at least temporarily) and changes the size and age structures of wild dog groups, how might this affect predator-prey relationships?

\section{Methods}

To investigate how changes to population size and age structure of wild dog groups produced by baiting (as shown in this paper) might affect the ability of wild dogs to handle large prey, the field records of Thomson (1992b) were re-examined. Thomson observed and recorded 272 interactions between collared wild dogs (and their companions) and kangaroos (Red Kangaroo Macropus rufus and Common Wallaroo M. robustus) in the Fortescue River area of Western Australia. The mean age of the known-age members of wild dog groups observed from an aircraft and identified by their collar transmitter frequencies (primarily), territories and pack associations, chasing or attacking kangaroos, were calculated from 205 wild 
dogs captured and aged during the study of Thomson (1992a). Wild dogs, first captured as pups $(n=23)$ or juveniles $(n=26)$, were assumed born mid-year in the previous breeding season [wild dogs are monoestrus (Corbett 2001)]. Adults were aged from pulp cavity-tooth width ratios from $X$-ray images of their canine teeth $(n=88)$ [method described in Thomson and Rose (1992) and further evaluated in Kershaw et al. (2005)] or, where they were not recovered at death, their age at first capture was based on tooth wear and general physical characteristics $(n=67)$.

Mean group size of the wild dogs observed 'chasing' (pursuing kangaroos) or 'attacking' kangaroos was calculated from Thomson's (1992b) recorded observations, 37 of which resulted in attacks. Attacks were defined as an aggressive physical encounter and/or killing of the prey. Descriptive statistics and $t$-tests were used to compare mean group size and mean age characteristics of dingoes successfully or unsuccessfully chasing kangaroos.

\section{Results}

The mean group size of wild dogs successfully chasing kangaroos that resulted in the kangaroo being attacked was 3.3 $( \pm 0.2)$ wild dogs (range 2-6). This contrasts $(t=6.31$, df $=240, P<0.00)$ with a mean group size of $1.8( \pm 0.1)$ dingoes (range 1-10) for unsuccessful chases that did not result in the kangaroo being attacked. The mean age of the knownage dingoes observed attacking kangaroos was also significantly greater than the mean age of the dingoes observed chasing, but not attacking kangaroos [attacks: 3.0 ( \pm 0.3$)$ years, range $1-7$; chases: 1.9 ( \pm 0.1 ) years, range $1-11$ years; $t=3.79$, df $=259, P<0.00]$.

\section{Evidence of Functional Change in Baited Wild Dogs}

This analysis investigated whether prey populations within baited and nil-treatment areas were comparable and remained so (i.e. responded similar to changes in seasonal conditions independent of baiting) or whether they diverged over time indicating the predator-prey relationship had changed. Divergence alone does not indicate a functional change unless associated with a change in prey selection.

\section{Methods}

Macropods (mostly Eastern Grey Kangaroo Macropus giganteus and Red-necked Wallaby M. rufogriseus) and Brush-tailed Possum (Trichosurus vulpecula) made up, respectively, $29 \%$ and $57 \%$ of the prey remains discovered in 653 wild dog scats collected on Mt Owen between 1994 and 1998 [details reported in Allen et al. (2012)]. Catling et al. (1997) compared alternative survey techniques and recommended track counts for detecting macropods and possums. PTI values for possums and macropods and their associated 95\% confidence intervals were plotted against time, and a paired $t$-test was used to compare mean PTI values between treatments. Because there were fewer PTI surveys conducted at Strathmore and for fewer years and because there was different preferred prey species in wild dog diets, the data from Strathmore were not included in this analysis.

Multiple regression analyses comparing the slopes of linear relationships between PTI values (dependent variable) and date, treatment and season (independent variables) and their interactions were examined. Because time series data can potentially be confounded by positive autocorrelation (i.e. the PTI/population size at one survey point is potentially dependent on the PTI/population size at the previous survey), the Durbin-Watson test of independence was applied to the residuals (Marques et al. 2013). Season, that is drought (May 1994 to November 1995 surveys) and postdrought when above-average rainfall was recorded (November 1995 to July 1998 surveys), was included to examine the effects of a substantial change in rainfall conditions and population trends.

\section{Results}

Macropod and possum PTI data were not auto-correlated (D-W statistic of 2.28 and 2.17 , respectively). Baited and nil-treatment area macropod PTI values were nearly identical when surveys first commenced in 1994 and remained similar during drought (near zero slope and mean PTIs not significantly different) but increased and diverged postdrought (Fig. 3) increasing substantially more in baited areas compared to nil-treatment areas. Mean PTIs were significantly different postdrought and over time between treatments, but not during the drought period, and multiple regression showed significant time, season, treatment and time*season and time*treatment effects (Table 1).

Possum PTI values were always higher in the nil-treatment area compared to the baited area (Fig. 4), and $t$-tests of mean PTI values and multiple regression analyses reflected this difference independent of season (Table 1). Linear trend lines fitted to possum PTI values (Fig. 4) were more or less parallel (with near zero slopes) during drought and postdrought periods between treatment areas and were not significantly different (i.e. not

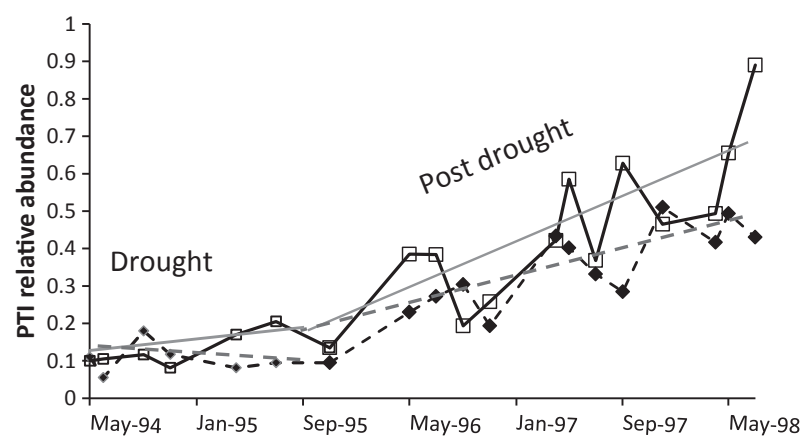

Figure 3. PTI values and linear trend lines for macropods in baited ( $\square$ symbols) and nil-treatment ( $\downarrow$ symbols) areas during drought and postdrought. 
Table 1. Results of $t$-tests of PTI means and multiple regression analyses Macropods

\begin{tabular}{|c|c|c|c|c|c|c|c|}
\hline \multicolumn{8}{|c|}{ Two-tailed t-test of PTI means } \\
\hline & Mean & SE & & $t=$ & & $d f$ & $P=$ \\
\hline \multicolumn{8}{|l|}{ All surveys } \\
\hline Baited & 0.35 & 0.05 & & \multirow[t]{2}{*}{-2.66} & & \multirow[t]{2}{*}{18} & \multirow[t]{2}{*}{0.008} \\
\hline Nil-treatment & 0.26 & 0.03 & & & & & \\
\hline \multicolumn{8}{|l|}{ Drought } \\
\hline Baited & 0.13 & 0.02 & & \multirow[t]{2}{*}{-1.05} & & \multirow[t]{2}{*}{6} & \multirow[t]{2}{*}{0.166} \\
\hline Nil-treatment & 0.10 & 0.01 & & & & & \\
\hline \multicolumn{8}{|l|}{ Postdrought } \\
\hline Baited & 0.48 & 0.05 & & \multirow[t]{2}{*}{-2.57} & & \multirow[t]{2}{*}{11} & \multirow[t]{2}{*}{0.013} \\
\hline Nil-treatment & 0.36 & 0.03 & & & & & \\
\hline \multicolumn{8}{|c|}{ Multiple regression ANOVA } \\
\hline Source & $R^{2}=$ & & $d f=$ & & $F=$ & & $P=$ \\
\hline Regression & $83.25 \%$ & & 5 & & 31.81 & & $<0.001$ \\
\hline Season & & & 1 & & 6.79 & & 0.014 \\
\hline Time & & & 1 & & 22.41 & & $<0.001$ \\
\hline Treatment & & & 1 & & 5.16 & & 0.030 \\
\hline Time*season & & & 1 & & 6.80 & & 0.014 \\
\hline Time*treatmen & & & 1 & & 5.35 & & 0.027 \\
\hline
\end{tabular}

\begin{tabular}{|c|c|c|c|c|c|}
\hline \multicolumn{6}{|l|}{ Possums } \\
\hline \multicolumn{6}{|c|}{ Two-tailed t-test of PTI means } \\
\hline \multicolumn{6}{|c|}{ All surveys } \\
\hline Baited & 0.04 & 0.01 & -6.93 & 18 & $<0.001$ \\
\hline Nil-treatment & 0.23 & 0.03 & & & \\
\hline \multicolumn{6}{|l|}{ Drought } \\
\hline Baited & 0.02 & 0.00 & 10.05 & 6 & $<0.001$ \\
\hline Nil-treatment & 0.10 & 0.01 & & & \\
\hline \multicolumn{6}{|l|}{ Postdrought } \\
\hline Baited & 0.05 & 0.01 & 7.96 & 11 & $<0.001$ \\
\hline Nil-treatment & 0.31 & 0.03 & & & \\
\hline \multicolumn{6}{|c|}{ Multiple Regression ANOVA } \\
\hline Source & $R^{2}=$ & $d f=$ & $F=$ & $P=$ & \\
\hline Regression & $75.77 \%$ & 5 & 20.01 & $<0.001$ & \\
\hline Season & & 1 & 0 & 0.992 & \\
\hline Time & & 1 & 0.78 & 0.385 & \\
\hline Treatment & & 1 & 8.06 & 0.008 & \\
\hline Time*season & & 1 & 0 & 0.965 & \\
\hline Time*treatment & & 1 & 8.73 & 0.006 & \\
\hline
\end{tabular}

Time $=$ date of survey; treatment $=$ baited versus nil-treatment areas; season $=$ surveys conducted during drought versus postdrought; and interactions between these variables.

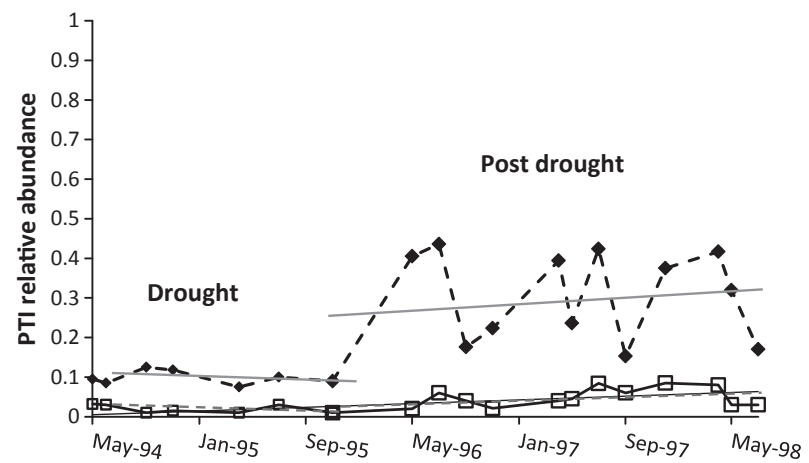

Figure 4. PTI values and linear trend lines for possums in baited ( $\square$ symbols) and nil-treatment areas ( symbols) during drought and postdrought. diverging). However, possum PTI values increased quickly in the nil-treatment area but not the baited area immediately postdrought yet remained relatively stable thereafter in both baited and nil-treatment areas.

\section{Discussion}

These data confirm that demographic differences in wild dog populations do occur as a result of baiting, as expected when some individuals are culled. Baiting programmes indeed reduce wild dog relative abundance, and although wild dog PTI values generally recover quickly after baiting, their age structures are different (Figs 1,2). Diverging trends in preferred prey PTIs subsequent to baiting (Figs 3,4) and correlation with greater calf losses where baiting has occurred (Allen 2014); (McGowan et al. 2014) suggest that these social changes and demographic differences can affect the way wild dogs interact with prey. Thomson's data show that larger and more mature wild dog groups are required to efficiently handle large prey. Wild dog populations postbaiting could therefore be less efficient at preying on large, difficult-tocatch species like kangaroos and are more dependent on easy-to-catch species like possums [see discussion of this in Allen et al. (2014)]. When preferred prey populations decline during a drought and large adult kangaroos are the alternative, wild dog groups comprised of fewer, younger and less experienced individuals would probably be forced to select less preferred prey. This could explain why in the study of Allen (2014), calf loss correlated with drought in baited areas but not in adjacent nil-treatment areas and why McGowan et al. (2014) found a significantly higher mean lactation failure on properties whose owners considered wild dogs impacted on their livestock and baited compared to those owners who did not consider wild dogs to be a problem and did nothing to control them $(11.81 \%$ and $6.29 \%$, respectively).

There is little difference in size between adult sheep, kangaroos and newborn calves (body weights of 50, 45-60 and $34-40 \mathrm{~kg}$, respectively). Prey behaviour and the degree of risk each prey spe- 
cies represents to the predator are important factors affecting prey selection (Mech 1988). The panicky fleeing behaviour of sheep (Allen \& Fleming 2004) and kangaroos elicits a chase and attack response by wild dogs. Domestic sheep have no antipredatory defences of any consequence against wild dogs but kangaroos use size (Shepherd 1981), speed and stamina to avoid predation. When in water (Corbett \& Newsome 1987; Purcell 2010) or backed against structures that prevent wild dogs from attacking from behind (Thomson 1992b), adult kangaroos will use their claws and powerful hind feet to defend themselves and will sometimes kill wild dog attackers. Cattle also have a variety of antipredatory behaviours that dissuade wild dogs from attacking calves. Adult cattle protect calves by aggressively charging at wild dogs and by keeping calves in nursery groups in the care of adult minders while their mothers are away (Allen 2014).

These data show that recolonised wild dog populations generally have adult-sized footprints (Fig. 2c) and, based on calibrations with known-age dingoes, they are mostly comprised of animals over 9 months of age with adult-sized footprints. Other studies show that dispersing wild dogs are mostly yearling females and yearling to 3-year-old males that disperse singularly or as small subgroupings from fractured packs (Thomson et al. 1992; Fleming et al. 2001). 'Yearling' also corresponds to an age when domestic dogs display excessive activity and are naturally inclined to problem behaviours (Wells \& Hepper 2000). Given that recolonised wild dog populations are mostly from this age group [(Thomson et al. 1992) and this study] and assuming they exhibit similar activity levels to domestic dogs at this age, a combination of unrestrained activity, inexperience at group hunting and necessity (hunger) probably increases the likelihood of wild dogs harassing calves. Torn ears and tails on calves [i.e. 'bitten cattle', reported by Hewitt (2009) to make up $10 \%$ of the economic loss caused by wild dogs] indicate that many calf attacks are unsuccessful.

Switching between prey species is thought to increase stability of population fluctuations and attenuate the impact that predators have on lower trophic levels (Choquenot \& Forsyth 2013; Allen et al. 2014). These empirical results support the model predictions of Choquenot and Forsyth (2013) that kangaroo populations would primarily be limited by bottom-up factors during drought and top-down effects (i.e. predation) in flush (postdrought) seasons and that baiting wild dogs would theoretically decouple the topdown effects in flush seasons potentially leading to over-abundant kangaroo populations (Fig. 3 postdrought).

\section{Implication for Future Management}

Wild dogs are likely to regulate (Pople et al. 2000) or limit kangaroo populations (Caughley et al. 1980), species that are major contributors to total grazing pressure and at times over-grazing (Wilson 1991). The role that wild dogs could play in biodiversity conservation and sustainable pasture management for rangeland livestock production is recognised but has received little attention and should be investigated further (Freudenberger et al. 1999; Johnson et al. 2007; Wicks \& Allen 2012).

Assuming a linear or strong positive relationship between wild dog numbers and their impact on calves (which underlies why some beef producers control wild dogs), one could conclude that wild dog baiting programmes were generally effective if short-term reductions in wild dog numbers (i.e. spoor or PTI values) were the sole criteria for measuring 'efficacy'. Measured against reductions in impact (predation loss of calves), however, baiting is seldom effective because:

1 Predation loss infrequently occurs in rangeland beef cattle when more preferred prey are available (Eldridge $\boldsymbol{e t}$ al. 2002); (Burns et al. 2010); (Allen 2014).

2 Ordinarily, wild dog populations have numerically recovered from baiting programmes before calving commences or, wild dog populations recover over summer when most calves are small and vulnerable [this paper and Bortolussi et al. (2005)] and,
3 Baiting appears to change the age structure and group size of recolonised wild dog populations making them more likely to be less efficient hunters of difficult-to-catch prey and more prone to harass calves [Allen (2014) and this paper].

Large-scale coordinated baiting of areas much greater than 200000 ha [the area baited in the study of Allen (2014) that had the greatest and most frequent predation loss], biannual baiting or baiting at the commencement of calving could theoretically address the issue of recolonisation during calving. However, these approaches do not change the more general findings that baiting can change the functional role of wild dogs; wild dogs could be key to limiting kangaroo numbers; and predation of calves occurs infrequently. Changing the timing of control programmes to those months when calving predominantly occurs and when predation is likely may reduce wild dog numbers and calf loss during critical (drought) periods. Otherwise, the potential indirect benefits of wild dogs to pasture productivity and biodiversity conservation through their impact on kangaroo populations could likely outweigh the infrequent negative impacts unmanaged wild dogs can have on rangeland beef cattle.

\section{Acknowledgements}

All procedures were undertaken in accordance with the Australian Code of Practice for the Care and Use of Animals for Scientific Purposes and were approved by the University of Queensland and Department of Natural Resources, Animal Ethics Committees (\#930 401). The Bureau of Resource Sciences and Queensland Department of Agriculture, Fisheries and Forestry jointly funded this project. I acknowledge Peter Thomson and Neville Kok of Agriculture Western Australia for their data on wild dog-kangaroo interactions, Tony Gonzalez who assisted in monitoring, and Rick Engeman and Allan Lisle for statistical advice. I also acknowledge colleagues and anonymous referees for editorial advice on the manuscript and declare no conflict of interest. 


\section{References}

Allen L. R. (2009) Best practice baiting: dispersal and seasonal movement of wild dogs (Canis lupus familiaris). In: Technical Highlights: Invasive Plant and Animal Research 200809. pp. 61-62. QLD Department of Employment, Economic Development and Innovation, Brisbane.

Allen L. R. (2014) Wild dog control impacts on calf wastage in extensive beef cattle enterprises. Animal Production Science 54, 214-220.

Allen L. and Engeman R. (2014) Evaluating and validating abundance monitoring methods in the absence of populations of known size: review and application to a passive tracking index. Environmental Science and Pollution Research doi: 10.1007/s11356-014-3567-3

Allen L. and Fleming P. J. S. (2004) Review of canid management in Australia for the protection of livestock and wildlife - potential application to coyote management. Sheep \& Goat Research Journal 19, 97-104.

Allen B. and Leung L. (2014) The (Non)effects of lethal population control on the diet of Australian Dingoes. PLOS ONE 9, Pe108251.

Allen L. R. and Sparkes E. C. (2001) The effect of dingo control on sheep and beef cattle in Queensland. Journal of Applied Ecology 38 76-87.

Allen B. L. and West P. (2013) Influence of dingoes on sheep distribution in Australia. Australian Veterinary Journal 91, 261-267.

Allen L., Engeman R. and Krupa H. (1996) Evaluation of three relative abundance indices for assessing dingo populations. Wildlife Research 23, 197-206.

Allen L., Goullet M. and Palmer R. (2012) The diet of the dingo (Canis lupus dingo and hybrids) in north-eastern Australia: a supplement to the paper of Brook and Kutt (2011). The Rangeland Journal 34, 211-217.

Allen B. L., Allen L. R., Engeman R. M. and Leung L. K.-P. (2014) Sympatric prey responses to lethal top-predator control: predator manipulation experiments. Frontiers in Zoology 11 30.

APVMA (2008) Review findings for sodium monofluoroacetate: The reconsideration of registrations of products containing sodium monofluoroacetate and approvals of their associated labels, Environmental Assessment. Australian Pesticides and Veterinary Medicines Authority, Canberra.

Bortolussi G., Mclvor J. G., Hodgkinson J. J., Coffey S. G. and Holmes C. R. (2005) The northern Australian beef industry, a snapshot. 2. Breeding herd performance and management. Australian Journal of Experimental Agriculture 45, 1075-1091.

Burns B. M., Fordyce G. and Holroyd R. G. (2010) A review of factors that impact on the capacity of beef cattle females to conceive, maintain a pregnancy and wean a calfImplications for reproductive efficiency in northern Australia. Animal Reproduction Science 122, 1-22.

Catling P. C., Burt R. J. and Kooyman R. (1997) A comparison of techniques used in a survey of the ground-dwelling and arboreal mammals in forests in north-eastern New South Wales. Wildlife Research 24, 417-432.
Caughley G., Grigg G. C., Caughley J. and Hill G. J. E. (1980) Does dingo predation control the densities of kangaroos and emus? Australian Wildlife Research 7, 1-12.

Choquenot D. and Forsyth D. M. (2013) Exploitation ecosystems and trophic cascades in nonequilibrium systems: pasture-red kangaroodingo interactions in arid Australia. Oikos 122, 1292-1306.

Corbett L. K. (2001) The Dingo in Australia and Asia. J.B Books, South Australia, Marleston.

Corbett L. and Newsome A. E. (1987) The feeding ecology of the dingo. III. Dietary relationships with widely fluctuating prey populations in arid Australia: an hypothesis of alternation of predation. Oecologia 74, 215-227.

Eldridge S. R., Shakeshaft B. J. and Nano T. J. (2002) The impact of wild dog control on cattle, native and introduced herbivores and introduced predators in central Australia, Final report to the Bureau of Rural Sciences. Parks and Wildlife Commission of the Northern Territory, Alice Springs.

Engeman R. (2005) Indexing principles and a widely applicable paradigm for indexing animal populations. Wildlife Research 32, 202-210.

Engeman R. and Allen L. (2000) Overview of a passive tracking index for monitoring wild canids and associated species. Integrated Pest Management Reviews 5, 197-203.

Estes J. A., Terborgh J., Brashares J. S. et al. (2011) Trophic downgrading of planet earth. Science 333, 301-306.

Fleming P., Corbett L., Harden R. and Thomson P. (2001) Managing the Impacts of Dingoes and Other Wild Dogs. Bureau of Rural Sciences, Canberra.

Fleming P. J. S., Allen B. L., Ballard G. and Allen L. R. (2012) Wild dog ecology, impacts and management in northern Australian cattle enterprises: a review with recommendations for R, D \& E investments. pp. 71. Meat \& Livestock Australia, North Sydney.

Freudenberger D., Wilson A. and Palmer R. (1999) The effects of perennial grasses, stocking rate and rainfall on sheep production in a semi-arid woodland of eastern Australia. The Rangeland Journal 21 199-219.

Hewitt L. (2009) Major economic costs associated with wild dogs in the Queensland grazing industry. Agforce, Brisbane.

Johnson C. N., Isaac J. L. and Fisher D. O. (2007) Rarity of a top predator triggers continentwide collapse of mammal prey: dingoes and marsupials in Australia. Proceedings of the Royal Society B: Biological Sciences 274 341-346.

Kershaw K., Allen L., Lisle A. and Withers K. (2005) Determining the age of adult wild dogs (Canis lupus dingo, C. I. domesticus and their hybrids): I. Pulp cavity: tooth width ratios. Wildlife Research 32, 1-5.

Kusak J., Skrbinsek A. M. and Huber D. (2005) Home ranges, movements, and activity of wolves (Canis lupus) in the Dalmatian part of Dinarids, Croatia. European Journal of Wildlife Research 51, 254-262.

Levi T. and Wilmers C. C. (2012) Wolvescoyotes-foxes: a cascade among carnivores. Ecology 93, 921-929.

Marques T. A., Buckland S. T., Bispo R. and Howland B. (2013) Accounting for animal density gradients using independent information in distance sampling surveys. Statistical Methods and Applications 22, 67-80.

McGowan M., Fordyce G., O'Rourke P. et al. (2014) Final report, Northern Australian beef fertility project: CashCow. pp. 301. Meat \& Livestock Australia Limited, North Sydney.

McKenzie J., Mifsud G., Dall D., Woolnough A. and Hall J. (2014) National Wild Dog Action Plan: Promoting and supporting communitydriven action for landscape-scale wild dog management. pp. 1-66. WoolProducers, Australia.

Mech L. D. (1988) The Wolf, the Ecology and Behavior of an Endangered Species. University of Minnesota Press, Minneapolis.

Nyahongo J. W. and Røskaft E. (2011) Perception of people towards lions and other wildlife killing humans, around Selous Game Reserve, Tanzania. International Journal of Biodiversity and Conservation 3, 110-115.

Pople A. R., Grigg G. C., Cairns S. C., Beard L. A. and Alexander P. (2000) Trends in the numbers of red kangaroos and emus on either side of the South Australian dingo fence: evidence for predator regulation? Wildlife Research 27, 269-276.

Prugh L., Stoner C., Epps C. et al. (2009) The rise of the mesopredator. BioScience 59, 779-791.

Purcell B. V. (2010) A novel observation of dingoes (Canis lupus dingo) attacking a swimming eastern grey kangaroo (Macropus giganteus). Australian Mammalogy 32, 201-204.

Saberwal V. K., Gibbs J. P., Chellam R. and Johnsingh A. J. T. (1994) Lion-human conflict in the Gir forest, India. Conservation Biology 8 , 501-507.

Schuette P., Creel S. and Christianson D. (2013) Coexistence of African lions, livestock, and people in a landscape with variable human land use and seasonal movements. Biological Conservation 157, 148-154.

Sergio F., Caro T., Brown D. et al. (2008) Top predators as conservation tools: ecological rationale, assumptions, and efficacy. Annual Review of Ecology, Evolution and Systematics 39, 1-19.

Shepherd N. C. (1981) Predation of red kangaroos, Macropus rufus, by the dingo, Canis familiaris dingo (Blumenbach) in north-western New South Wales. Wildlife Research 8, 255-262.

Thomson P. C. (1992a) The behavioural ecology of dingoes in north-western Australia: I. The Fortescue River study area and details of captured dingoes. Wildlife Research 19, 509518.

Thomson P. C. (1992b) The behavioural ecology of dingoes in north-western Australia: III. Hunting and feeding behaviour, and diet. Wildlife Research 19, 531-541.

Thomson P. C. and Rose K. (1992) Age determination of dingoes from characteristics of canine teeth. Wildlife Research 19, 597 599.

Thomson P. C., Rose K. and Kok N. E. (1992) The behavioural ecology of dingoes in north-western Australia: VI. Temporary extraterritorial movements and dispersal. Wildlife Research 19, 585-595.

Wang S. W. and Macdonald D. W. (2006) Livestock predation by carnivores in Jigme Singye Wangchuck National Park, Bhutan. Biological Conservation 129, 558-565. 


\section{R E S E A R C H R E P ORT}

Wells D. L. and Hepper P. G. (2000) Prevalence of behaviour problems reported by owners of dogs purchased from an animal rescue shelter. Applied Animal Behaviour Science 69, 55-65.
Wicks S. and Allen B. L. (2012) Returns on investment in wild dog management: cattle production in the South Australian arid lands. In: 56th Australian Agricultural Resource Economics Society Conference,
AARES, Fremantle, Western Australia, pp. $1-22$.

Wilson A. (1991) Forage utilization by sheep and kangaroos in a semi-arid woodland. The Rangeland Journal 13, 81-90. 